\title{
Prevalence of four different subgenotypes of genotype 4 hepatitis $E$ virus among swine in the Shanghai area of China Yijia Yan ${ }^{\dagger}$, Wen Zhang ${ }^{\dagger}$, Quan Shen, Li Cui and Xiuguo Hua*
}

\author{
Address: Shanghai Key laboratory of Veterinary Biotechnology, School of Agriculture and Biology, Shanghai JiaoTong University, 800 Dongchuan \\ Road, Shanghai 200240, PR China \\ Email: Yijia Yan - y_yan11@sjtu.edu.cn; Wen Zhang - z0216wen@sjtu.edu.cn; Quan Shen - Shenquanfly@yahoo.com; Li Cui - lcui@sjtu.edu.cn; \\ Xiuguo Hua* - hxg@sjtu.edu.cn \\ * Corresponding author †Equal contributors
}

Published: 3I May 2008

Acta Veterinaria Scandinavica 2008, 50:12 doi:10.1186/175I-0147-50-12

This article is available from: http://www.actavetscand.com/content/50/I/I2

(c) 2008 Yan et al; licensee BioMed Central Ltd.

This is an Open Access article distributed under the terms of the Creative Commons Attribution License (http://creativecommons.org/licenses/by/2.0), which permits unrestricted use, distribution, and reproduction in any medium, provided the original work is properly cited.
Received: 19 January 2008

Accepted: 31 May 2008

\begin{abstract}
Background: Hepatitis E virus (HEV) is a zoonotic pathogen of which swine was reported as major reservoirs. HEV has been divided into 4 different genotypes according to phylogenetic analysis. Recent reports showed that genotype $4 \mathrm{HEV}$ is freely transmitted between humans and swine in eastern China, including Shanghai area. This paper investigated the recent infection status of HEV among swine population of Shanghai area in China.

Methods: 480 swine faecal specimens were collected from 23 farms which distribute all over Shanghai from September to November, 2007 and tested for the presence of HEV RNA by the polymerase chain reaction (PCR).

Results: Our results showed that $26.1 \%(6 / 23)$ of the swine farms were positive for HEV RNA and the positive rate of the six farms were ranged from $9.1 \%$ to $33.3 \%$. The HEV RNA positive rate for total samples were $5 \%(24 / 480)$. The resulted positive band specific for HEV was sequenced and sequence analysis indicated that all of these isolates belonged to genotype $4 \mathrm{HEV}$. Phylogenetic analysis showed that the 24 isolates clustered into 4 distinct subgroups, sharing $83.3-89.7 \%$ intersubgroup and $97-99 \%$ intra-subgroup identities. More over, isolates in three of the four subgroups closely clustered with previous identified strains, sharing up high to $97 \%$ identity with them.
\end{abstract}

Conclusion: These results suggested that there were 4 different subgenotypes of HEV prevalent in Shanghai, and some of them may not be indigenous to Shanghai but introduced from other geographic regions.

\section{Background}

Hepatitis E virus (HEV), a member of the genus Hepevirus, is a non- enveloped virus with a positives- stranded RNA genome approximately7.2 kb in length [1]. HEV has been proven to transmit by the faecal- oral route, and outbreaks of hepatitis $E$ are attributed to water contaminated with HEV. HEV and antibodies to HEV have been reportedly found in a wide variety of animals, especially swine
[2-5]. A hypothesis has arisen that zoonosis is involved in the transmission of HEV, especially for the cases in nonendemic areas. Recently, more direct evidences for zoonotic HEV transmission were reported [6]

The first animal strain of HEV, designated swine HEV, to be isolated and characterized was obtained from a pig in the United States [7]. Subsequently, many HEV samples 
from swine in over a dozen countries have been identified. HEV isolates were divided into four distinct genotypes according to sequence and phylogenetic analyses. Genotype 1 was previously believed to only infect humans, but reportedly detected from a pig in Cambodia recently [8]. Genotype 2 has only been identified in humans in Mexico and Africa (Nigeria, Chad). Genotype 3 is prevalent in swine herds and humans all over the world and Chinese genotype $3 \mathrm{HEV}$ was first discovered in eastern China in 2006 [9]. Genotype $4 \mathrm{HEV}$ was first detected in humans in 1993 [10] and is mainly distributed in China, Japan, India, Indonesia, and Vietnam. Genotype $4 \mathrm{HEV}$ has a wide host range, being prevalent in humans, swine, and some other animals. These four genotypes of virus are thought to comprise a single serotype [11]. Hepatitis E was first recognised in China after a large epidemic in the south part of Xinjiang Uighur autonomous region [12]. Since 2000, Genotype $4 \mathrm{HEV}$ has become the dominant cause of hepatitis $\mathrm{E}$ disease in China [13]. A recent report showed that genotype $4 \mathrm{HEV}$ is freely transmitted between humans and swine in eastern China [14]. In the present study, we tested the 480 faecal samples collected from 23 commercial pig farms in Shanghai area of China for HEV RNA in order to investigate the current status of HEV prevalence in the swine population.

\section{Materials and methods Samples}

480 swine faecal specimens were obtained from 23 swine farms in swine- farming districts of Shanghai city in China from September to November, 2007. The sampling sites were marked as black point in figure 1, a map of Shanghai. All the swine sampled from were 2-4 months old. Specimens were carefully collected to avoid any contamination. All the samples were converted to $10 \%(\mathrm{w} / \mathrm{v})$ suspensions in PBS (0.01 M, pH 7.2-7.4) immediately following the sampling. These samples were shipped, frozen, to our laboratory and stored at $-80^{\circ} \mathrm{C}$ prior to analysis.

\section{Nucleic acid extraction and designing of PCR primers}

Faecal sample suspensions were clarified by centrifugation at $5000 \mathrm{~g}$ for $45 \mathrm{~min}$, and $100 \mu \mathrm{l}$ aliquot of the clarified material was used for viral RNA extraction. Total RNA was extracted by using TRIzol reagent (Invitrogen, USA) in accordance with the manufacturer's protocol. The RNA was finally dissolved in $20 \mu \mathrm{l}$ RNase- free water. The primers used for HEV sequence amplification in this study were those previously described in reference [15]. The primers were HEV1 [forward primer; 5'-AATTATGCC(T)CAGTAC(T)CGG(A)GTTG-3'] and HEV2 [reverse primer; 5'-CCCTTA(G)TCC(T)TGCTGA(C)GCATTCTC3'] for the first round of PCR and HEV3 [forward primer; 5'-GTT(A)ATGCTT(C)TGCATA(T)CATGGCT-3'] and
HEV4 [reverse primer; 5'-AGCCGACGAAATCAATTCTGTC-3'] for the second round. This set of primers was designed to produce a 348- nt segment of open reading frame (ORF) 2, and were capable of detecting all four known HEV genotypes. Letters in parentheses indicate degenerate bases.

\section{RT- PCR and nested PCR}

Reverse transcriptase PCR (RT- PCR) was performed by using TaKaRa RNA PCR kit (TaKaRa, Japan) according with the manufacturer's instructions. Briefly, $4 \mu \mathrm{l}$ of RNA solution was analyzed by RT-PCR, plus $2 \mu \mathrm{l} 25 \mathrm{mM}$ $\mathrm{Mg} 2+, 1 \mu \mathrm{l} 10 \times$ RT buffer, $1 \mu \mathrm{l} 10 \mathrm{mM}$ (each) dNTP, 20 pmol reverse primer (primer HEV4), $10 \mathrm{U}$ of RNase inhibitor, and 2.5 U of AMV Reverse Transcriptase XL in a total volume of $10 \mu \mathrm{l}$. After incubation for $30 \mathrm{~min}$ at $42^{\circ} \mathrm{C}$, the mixture was incubated for $5 \mathrm{~min}$ at $99^{\circ} \mathrm{C}$ to denature the products and then chilled on ice. $10 \mu \mathrm{l}$ of the resulting cDNA was amplified by the universal RT- PCR assay using PerfectShot Taq (Loading dye Mix) DNA polymerase (TaKaRa, Japan). Briefly, RT- PCR was conducted in a total volume of $50 \mu \mathrm{l}$, containing $10 \mathrm{ul}$ cDNA solution, $25 \mathrm{ul}$ Loading dye Mix and 25 pmol both sense primer and antisense primer. The PCR parameters for the first- round PCR included a denaturation step at $95^{\circ} \mathrm{C}$ for $9 \mathrm{~min}$, followed by 39 cycles of denaturation for $1 \mathrm{~min}$ at $94^{\circ} \mathrm{C}$, annealing for $1 \mathrm{~min}$ at $42^{\circ} \mathrm{C}$, extension for $2 \min$ at $72^{\circ} \mathrm{C}$, and a final incubation at $72^{\circ} \mathrm{C}$ for $7 \mathrm{~min}$. $10 \mathrm{ul}$ products of firstround PCR were used as template for the second-round PCR. The parameters for the second- round PCR were similar to the first-round.

\section{Nucleotide sequencing}

The nested PCR products were analyzed in a $1.5 \%$ agarose gel containing $0.5 \mathrm{ug} / \mathrm{mL}$ ethidium bromide. The expected DNA band specific for the HEV was excised from the gel, purified with the AxyPrep DNA Gel Extraction kit (Axygen, USA) and cloned into pMD T- Vector (TaKaRa, Japan). Both strands of the inserted DNA amplicons were sequenced in a DNA analyzer (Applied Biosystems 3730 DNA Analyzer; Invitrogen, USA).

Standard precautions were used for all procedures to reduce the possibility of sample contamination by amplified DNA molecules. A faecal specimen from a pig infected with swine genotype $4 \mathrm{HEV}$ was used as positive control. PBS instead of faecal suspension, and water instead of RNA samples or cDNA template were used as negative controls in the nucleic acid extraction and RTPCR, respectively.

\section{Phylogenetic analysis}

Sequences were aligned using ClustaX v1.8 or MegAlign program in the DNASTAR software package. Phylogenetic analysis was constructed using the Mega 4 software [16]. 


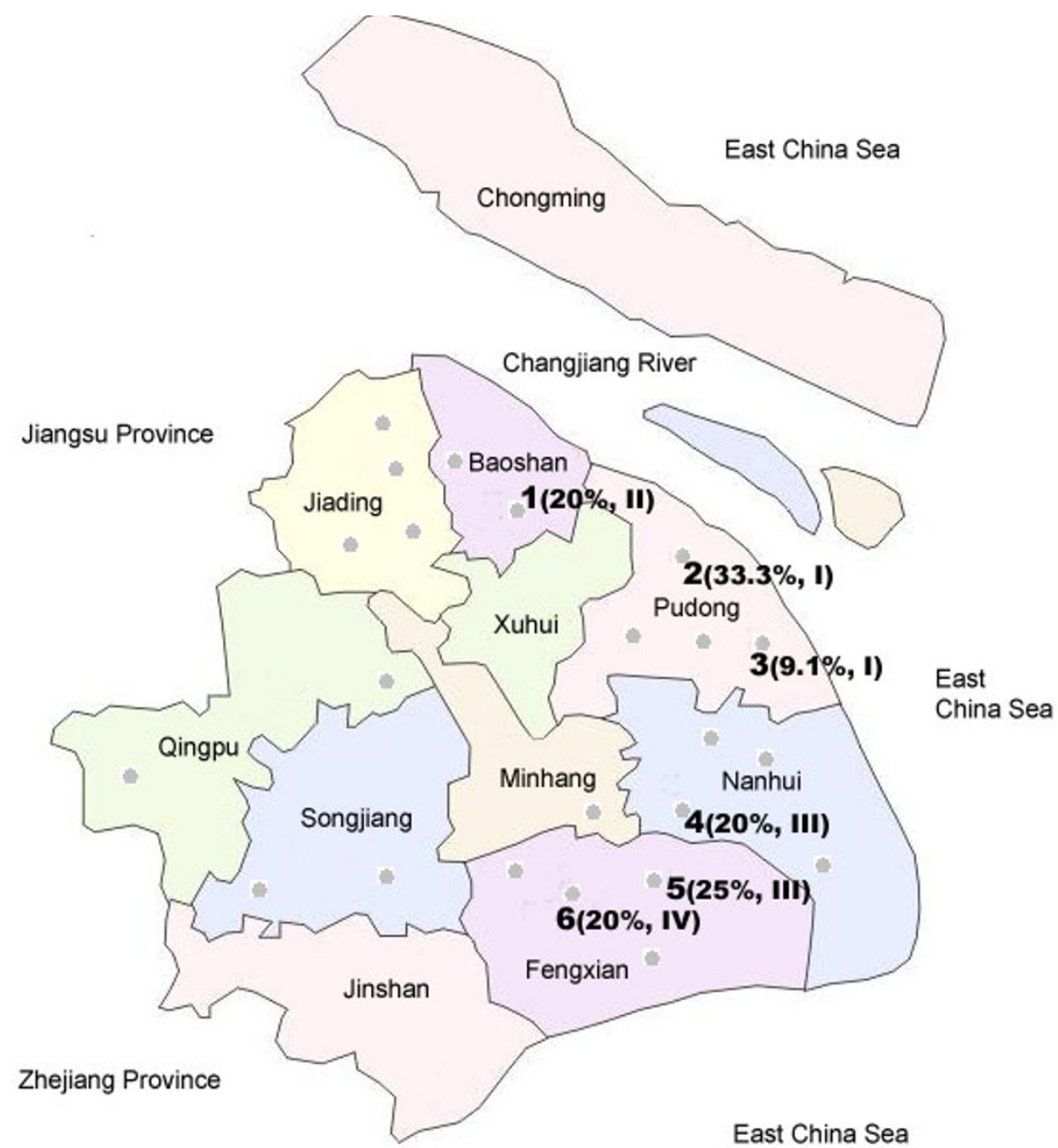

Figure I

The maps of Shanghai of China. Black points indicate the sites of 23 farms we sampled from. "I", "2", "3", "4", "5" and "6" show six HEV positive farms; the HEV positive rate and subgroup that the HEV strains belong to are indicated in the bracket.

Prototype HEV strains used as references in the analysis and their GenBank accession numbers are showed in figure 2 . The sequences determined in current study were deposited in GenBank, isolate names were indicated in figure 2 and the accession numbers are EU375319EU375342.

\section{Result}

\section{Occurrence of HEV}

Table 1 shows the results of detection of HEV-RNA in faecal samples from HEV positive farms. Six out of $23(26.1 \%)$ farms from which we sampled were tested positive for HEV. Among the 6 farms, the HEV positive rate of faecal samples ranged from $9.1 \%$ to $33.3 \%$. Figure 1 shows the six sites of the HEV positive farms (marked with Arabic numeral 1-6) and the HEV positive rate of each farm (indicated in the bracket). The overall HEV positive rate for all the samples was 5\% (24/480).

\section{Phylogenetic analysis}

The PCR- amplified products of 24 isolates were sequenced. Phylogenetic analyses were conducted using the sequence alignments of these isolates and the references. Figure 1 is the phylogenetic tree constructed based on the 24 isolates in this study and the references by using Mega 4.0 software. Result showed that the isolates we determined all belonged to genotype $4 \mathrm{HEV}$ and they cluster into four different subgroups. The four subgroups clustered closely with previously identified isolates: AY596311 (Xinjiang, Western China), AJ344192 (Beijing, Northern China), AB220978 (Japan), and DQ450079 (Xinjiang, Western China), respectively. Figure 3 is the 


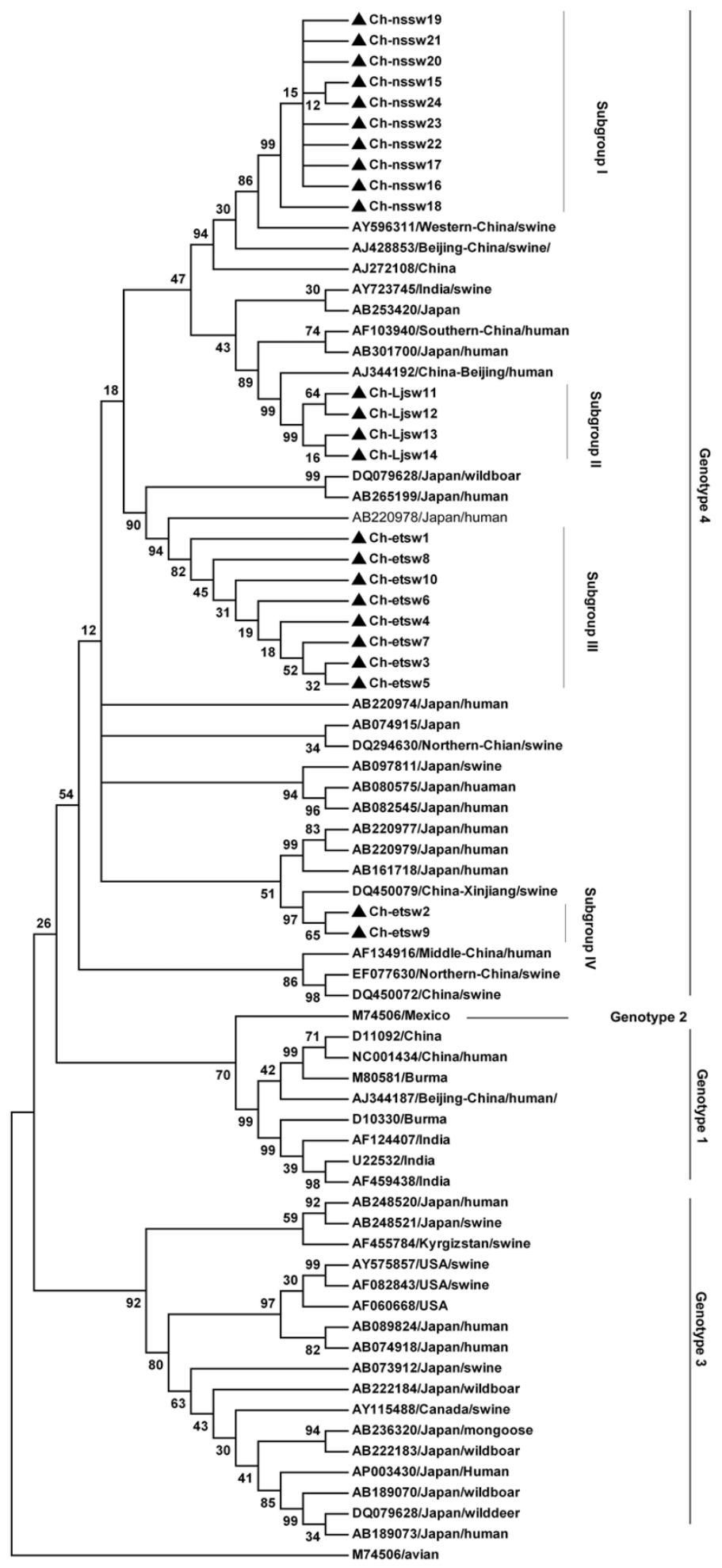

Figure 2

Phylogenetic tree constructed by alignment of the348- nt nucleotide sequence of ORF2 from isolates in this study and references of other animal and human HEV isolates, using the neighbor- joining method and evaluated using the interior branch test method with Mega 4 software. Percent bootstrap support is indicated at each node. GenBank accession no., source and country of origin are indicated. The isolates in this study were marked with solid triangle. Avian HEV strain is included as outgroup. 
Table I: Detection of HEV-RNA in faecal samples from HEV positive farms.

\begin{tabular}{ccc}
\hline No. of farm & Positive samples/Total analyzed (\%) & Subgroup of the strains \\
\hline I & $4 / 20(20 \%)$ & II \\
2 & $8 / 24(33.3 \%)$ & I \\
3 & $2 / 22(9.1 \%)$ & III \\
4 & $3 / 15(20 \%)$ & III \\
5 & $5 / 20(25 \%)$ & IV \\
\hline
\end{tabular}

phylogenetic tree constructed based on the consensus sequences of strains in each subgroup. From the phylogenetic tree, we can see that the phylogenetic relation among the 4 subgroups showed in figure 3 was identical to that of figure 2 .

\section{Divergence and percent identity}

The identity among isolates we determined in each subgroup and their closely related strains referenced from GenBank were analyzed. Result showed that intra-subgroup identities of the four subgroups were ranged from $97 \%$ to $99 \%$. The identities between the four subgroups and the closely clustered previous strains were 92\% (subgroup1 to AY596311), 97\% (subgroup 2 to AJ344192), 92-97\% (subgroup 3 to $\underline{\mathrm{AB} 220978 \text { ), and }}$ 97\% (subgroup 4 to DQ450079), respectively. The source sites of the 4 subgroups are shown in figure 1 (marked with Roman number in bracket). We can see that subgroup I contains the strains identified in farm 2 and 3, and subgroup III includes the strains found in farm 4 and 5, and the strains in each of the two subgroups have high nucleotide sequence homology (97-99\%), suggesting these strains from each two farms were from a common source of infection. Table 2 showed the percent identity and divergence among the 4 subgroups. The identity and divergence among the four subgroups were ranged from $83.3-89.7 \%$ and $12.4-19.6$, respectively. The overall mean distance for the 4 subgroups was 0.159 .

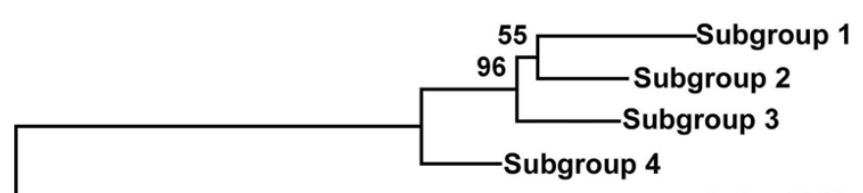

Avian HEV

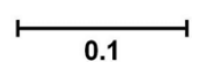

Figure 3

Phylogenetic tree constructed by alignment of consensus sequence of the isolates in each subgroup, using the neighbor- joining method and evaluated using the interior branch test method with Mega 4 software. Percent bootstrap support is indicated at each node. Avian HEV strain is included as outgroup.

\section{Sequence alignment}

The consensus nucleotide sequence of each subgroup and the coding amino-acid sequences were aligned using DNAstar software. The results indicated that though the 4 subgroups showed high diversity on the nucleotide level (22.7\% of the nucleotide sites have base substitution), they were very conservative on the amino-acid level, only having two sites $(1.8 \%)$ of amino-acid replacement. Because these sequences are part of the ORF2 region encoding a capsid protein of HEV virions, the conservation probably contributes to the same serotype of these strains.

\section{Discussion}

Accumulated evidence indicates that HEV infection is a zoonosis which involves various animal reservoirs. Pigs stand out as being an animal group with the highest positive rate for HEV RNA, where the isolates were shown to be closely associated with those from humans [17-20]. Among the 4 distinct genotypes, genotype 4 has been dominant in China [13]. Recently, genotype 4 HEV was reported to be widely distributed in humans and swine in Eastern China [14], including Shanghai. In the present study, 24 genotype $4 \mathrm{HEV}$ isolates were detected in 480 pigs in Shanghai of China, which were phylogenetically divided into four different subgroups, and the isolates in subgroup 2, and subgroup 3 shared $97 \%$ and $92-97 \%$ identity with two human isolates, AJ344192 and AB220978, respectively. The two human isolates were from Beijing of China and Japan, respectively [21,22], which are geographically significantly far from Shanghai. Therefore, we speculated that this may owe to the traveling of humans who were infected with these virus, or trading pigs which carrying these virus.

Table 2: The divergence and percent identity between the 4 subgroups (subgroup I-IV) identified in the present study.

\begin{tabular}{cccc}
\hline \multicolumn{4}{c}{ Percent Identity } \\
I & 89.7 & 87.0 & 83.3 \\
13.7 & II & 88.8 & 85.8 \\
14.7 & 12.4 & III & 85.8 \\
19.6 & 16.3 & 16.2 & IV \\
\hline \multicolumn{3}{c}{ Divergence } \\
\hline
\end{tabular}


Swine HEV isolates identified from the same geographic region tended to cluster together [23], and this point was confirmed by some recent studies $[24,25]$. In the present study, the determined 24 isolates were from 6 different farms in the same geographic region, and these strains phylogenetically clustered into genotype 4 group and formed 4 different subgroups, sharing $83.3-89.7 \%$ intersubgroup and $98-99 \%$ intra-subgroup identity. This rather low inter-subgroup nucleotide sequence homology among the strains suggested that these Shanghai swine HEV strains represents four distinct variants among the genotype 4 isolates and the HEV prevalence in Shanghai swine is complicated. Phylogenetic analysis also showed that three of the 4 subgroups had closely clustered with three previously identified strains isolated in different regions even countries, sharing up high to $97 \%$ identity with them. This suggested that some the HEV strains prevalent in Shanghai swine populations were not Shanghaiindigenous.

Shanghai lies in the most southern eastern part of China. It is one of the most developed and open cities and has the largest number of trading activities in China. Some evidences indicate that $60 \%$ of pigs consumed in Shanghai were imported from other regions of China. Shanghai had history of introducing different species of excellent domestic pigs from other regions of China and even abroad for commercial raising. Therefore, we cannot rule out the possibility of an outside source for some of the isolates in the four different subgroups in the present study: they may spread unnoticedly among pigs and humans through pigs trading or people traveling, as suggested in Taiwan and Japan [26,27]. With the increasing of HEV strains, one can look at reasonably comprehensive collection of international strains for phylogenetic analysis to elucidate the impact of pig trading and humans traveling, and clearly clarify the issues in the future.

Our results suggested the strains that from farm 2 and 3 , and that from farm 4 and 5 were from a common source of infection, respectively, sharing relatively high identity (97-99\%). Moreover, farm 2 and 4 are near from farm 3 and 5, respectively (figure 1). This may imply HEV can transmit from one farm to the farm nearby through a certain route, such as faecal contamination and people movement, suggesting that the feaces of pig need to be treated under strict conditions and people's movement between pig farms should be well controlled. Although farm 2 and 3 have HEV strains clustered closely in the same subgroup prevalent and are geographically near, the HEV positive rate of them are relatively different $(33.3 \%$ and $9.1 \%$ ). This may be caused by non-viral factors, such as sanitary conditions, hosts, facilities, or type of farming.
Although HEV of different genotypes are genetically very heterogenic on nucleotide level, some universal primers were designed which can detect HEV strains from all four known genotypes $[15,28]$. This set of RT-PCR primers used here belong to one of them and were used in many previously studies. In this study, positive control were added through out experiments and the HEV isolates we determined using this set of primers all belonged to genotype $4 \mathrm{HEV}$, without genotype 3 isolates. This was contrast to the study results of Ning [9] and our previous data (unpublished), which showed genotype 3 HEV strains existed in Shanghai of China, based on detection of swine serum or faecal specimens collected before 2006. Different sampling site and time may contribute to this point. A definitive conclusion for this issue should be drawn by more research data.

\section{Conclusion}

The genotype $4 \mathrm{HEV}$ isolates prevalent in swine populations in Shanghai area can be divided into 4 subgenotypes and the sequence identities among them ranged from $83.3 \%$ to $89.7 \%$. Based on the phylogenetic analysis, the 4 subgenotypes closely clustered with 4 previously identified stains from other different geographic regions, respectively, suggesting that some of the HEV isolates may not be indigenous to Shanghai.

\section{Competing interests}

The authors declare that they have no competing interests.

\section{Authors' contributions}

All authors participated in the planning of the project. XH was the leader of the project. YY and WZ collected all samples and performed the detecting experiments for HEV RNA. WZ and QS done the phylogenetic analysis. All authors read and approved the final manuscript.

\section{Acknowledgements}

This work was supported by Key Project of Shanghai Science and Technology Committee of China under Grant No.063919121.

\section{References}

I. Reyes GR, Purdy MA, Kim JP, Luk KC, Young LM, Fry KE, Bradley $D W$ : Isolation of a cDNA from the virus responsible for enterically transmitted non- A, non- B hepatitis. Science 1990 , 247: I335-I339.

2. Shukla P, Chauhan UK, Naik S, Anderson D, Aggarwal R: Hepatitis $E$ virus infection among animals in northern India: an unlikely source of human disease. J Viral Hepat 2007, 14:3 10-3 I 7 .

3. Saad MD, Hussein HA, Bashandy MM, Kamel HH, Earhart KC, Fryauff DJ, Younan M, Mohamed AH: Hepatitis E virus infection in work horses in Egypt. Infect Genet Evol 2007, 7:368-73.

4. Goens SD, Perdue ML: Hepatitis $E$ viruses in humans and animals. Anim Health Res Rev 2004, 5: I 45-156.

5. Tei S, Kitajima N, Takahashi K, Mishiro S: Zoonotic transmission of hepatitis $\mathrm{E}$ virus from deer to human beings. Lancet 2003, 362:371-373.

6. Li TC, Chijiwa K, Sera N, Ishibashi T, Etoh Y, Shinohara Y, Kurata Y, Ishida M, Sakamoto S, Takeda N, Miyamura T: Hepatitis E virus 
transmission from wild boar meat. Emerg Infect Dis 2005, I I:I958-1960.

7. Meng XJ, Purcell RH, Halbur PG, Lehman JR, Webb DM, Tsareva TS, Haynes JS, Thacker BJ, Emerson SU: A novel virus in swine is closely related to the human hepatitis E virus. Proc Natl Acad Sci USA 1997, 94:9860-9865.

8. Caron M, Enouf V, Than SC, Dellamonica L, Buisson Y, Nicand E: Identification of genotype $I$ hepatitis $E$ virus in samples from swine in Cambodia. J Med Microbiol 2006, 44:3440-3442.

9. Ning H, Niu Z, Yu R, Zhang P, Dong S, Li Z: Identification of genotype 3 hepatitis $E$ virus in faecal samples from a pig farm located in a Shanghai suburb. Vet Microbiol 2007, I 21:125-130.

10. Huang $R$, Nakazono N, Ishii K, Kawamata O, Kawaguchi R, Tsukada $Y$ : Existing variations on the gene structure of hepatitis $E$ virus strains from some regions of China. J Med Microbiol I995, 47:303-308.

II. Panda SK, Thakral D, Rehman S: Hepatitis E virus. Rev Med Virol 2007, I 7:15I-80.

12. Zhuang $H$, Cao $X Y$, Liu $C B$, Wang GM: Enterically transmitted non- A, non- B hepatitis in China. In Viral hepatitis $C, D$, and $E$ Edited by: Shikata T, Purcell RH, Uchida T. Amsterdam- New YorkOxford: Excerpta Medica; 1991:277-285.

13. Wang Y: Epidemiology, molecular biology and zoonosis of genotype IV hepatitis E in China. Chin J Epidemiol 2003, 24:618-622.

14. Zheng Y, Ge S, Zhang J, Guo Q, Ng MH, Wang F, Xia N, Jiang Q: Swine as a principal reservoir of hepatitis $E$ virus that infects humans in eastern China. J Infect Dis 2006, 193:1643-1649.

15. Cooper K, Huang FF, Batista L, Rayo CD, Bezanilla JC, Toth TE, Meng $\mathrm{XJ}$ : Identification of genotype 3 hepatitis E virus (HEV) in serum and faecal samples from pigs in Thailand and Mexico, where genotype $I$ and 2 HEV strains are prevalent in the respective human populations. J Clin Microbiol 2005, 43:1684-1688.

16. Mega- Molecular Evolutionary Genetic Analysis [http:// www.megasoftware.net/]

17. Lu L, Li C, Hagedorn CH: Phylogenetic analysis of global hepatitis $\mathrm{E}$ virus sequences: genetic diversity, subtypes and zoonosis. Rev Med Virol 2006, 16:5-36.

18. Satou K, Nishiura H: Transmission dynamics of hepatitis $E$ among swine: potential impact upon human infection. $B M C$ Vet Res 2007, 3:9.

19. Meng XJ: Swine hepatitis E virus: cross-species infection and risk in xenotransplantation. Curr Top Microbiol Immunol 2003, 278: $185-216$.

20. Takahashi M, Nishizawa T, Miyajima H, Gotanda $Y$, lita T, Tsuda $F$, Okamoto H: Swine hepatitis E virus strains in Japan form four phylogenetic clusters comparable with those of Japanese isolates of human hepatitis E virus. J Gen Virol 2003, 84:85 I-862.

21. Inoue J, Nishizawa T, Takahashi M, Aikawa T, Mizuo H, Suzuki K, Shimosegawa T, Okamoto $\mathrm{H}$ : Analysis of the full-length genome of genotype 4 hepatitis $E$ virus isolates from patients with fulminant or acute self-limited hepatitis E. I Med Virol 2006, 78:476-484

22. Wang Y, Zhang H, Li Z, Gu W, Lan H, Hao W, Ling R, Li H, Harrison T]: Detection of sporadic cases of hepatitis E virus (HEV) infection in China using immunoassays based on recombinant open reading frame 2 and 3 polypeptides from HEV genotype 4. J Clin Microbiol 200I, 39:4370-4379.

23. Huang FF, Haqshenas G, Guenette DK, Halbur PG, Schommer SK, Pierson FW, Toth TE, Meng XJ: Detection by reverse transcription- PCR and genetic characterization of field isolates of swine hepatitis $E$ virus from pigs in different geographic regions of the United States. I Clin Microbiol 2002, 40: I 326- I 332

24. Wibawa ID, Suryadarma IG, Mulyanto , Tsuda F, Matsumoto $Y$, Ninomiya M, Takahashi M, Okamoto H: Identification of genotype 4 hepatitis $E$ virus strains from a patient with acute hepatitis E and farm pigs in Bali, Indonesia. J Med Virol 2007, 79: II38-1146.

25. Munné MS, Vladimirsky S, Otegui L, Castro R, Brajterman L, Soto $S$, Guarnera E, Molina V, Monfellano M, Schlauder GG, González JE: Identification of the first strain of swine hepatitis $E$ virus in South America and prevalence of anti- HEV antibodies in swine in Argentina. J Med Virol 2006, 78:1579-83.
26. Wu JC, Chen CM, Chiang TY, Tsai WH, Jeng WJ, Sheen IJ, Lin CC, Meng XJ: Spread of hepatitis E virus among different- aged pigs: two- year survey in Taiwan. J Med Virol 2002, 66:488-492.

27. Inoue J, Takahashi M, Ito K, Shimosegawa T, Okamoto H: Analysis of human and swine hepatitis E virus (HEV) isolates of genotype 3 in Japan that are only $8 I-83 \%$ similar to reported HEV isolates of the same genotype over the entire genome. J Gen Virol 2006, 87:2363-2369.

28. Inoue J, Takahashi M, Yazaki Y, Tsuda F, Okamoto H: Development and validation of an improved RT- PCR assay with nested universal primers for detection of hepatitis $E$ virus strains with significant sequence divergence. J Virol Methods 2006, 137:325-333.
Publish with Biomed Central and every scientist can read your work free of charge

"BioMed Central will be the most significant development for disseminating the results of biomedical research in our lifetime. "

Sir Paul Nurse, Cancer Research UK

Your research papers will be:

- available free of charge to the entire biomedical community

- peer reviewed and published immediately upon acceptance

- cited in PubMed and archived on PubMed Central

- yours - you keep the copyright

Submit your manuscript here:

http://www.biomedcentral.com/info/publishing_adv.asp
BioMedcentral 